\title{
The cardiovascular benefits of low-dosage acetylsalicylic acid
}

\author{
Priya Koilpillai MD, N. Sudhir Nishtala MD
}

Cite as: CMAJ 2019 October 28;191:E1194. doi: 10.1503/cmaj.191037

CMAJ Podcasts: author interview at https://soundcloud.com/cmajpodcasts/191037-five

1

Acetylsalicylic acid has established benefit in the secondary

prevention of cardiovascular disease

The increased risk of severe bleeding with use of acetylsalicylic acid (ASA) (odds ratio 2.2, 95\% confidence interval $[\mathrm{Cl}]$ 1.4-3.4) is outweighed by the $21 \%$ reduction $(95 \% \mathrm{Cl} 0.72-0.88)$ in the odds of recurrent atherosclerotic events (coronary artery disease, ischemic stroke or transient ischemic attack) and $13 \%$ reduction $(95 \% \mathrm{Cl} 0.76-0.98)$ in the odds of all-cause mortality. ${ }^{1}$

2

The benefit of ASA in the primary prevention of cardiovascular disease is offset by potential bleeding risks

The use of ASA for primary prevention was examined in a meta-analysis of 13 trials involving 164225 participants. ${ }^{2}$ Use of ASA was associated with a lower risk of cardiovascular events (hazard ratio [HR] 0.89, 95\% credible interval 0.840.95; number needed to treat 241) and an increased risk of major bleeding (HR $1.43,95 \%$ credible interval 1.30-1.56; number needed to harm 210$){ }^{2}$

Patients with diabetes, despite their increased cardiovascular risk, have questionable benefit from ASA used for primary prevention The ASCEND (A Study of Cardiovascular Events in Diabetes) trial in 2018 evaluated primary prevention with ASA in 15480 patients with diabetes. ${ }^{3}$ At 7 years, a $1.1 \%$ absolute risk reduction in serious cardiovascular events was counterbalanced by an associated $0.9 \%$ increase in major bleeding with use of ASA; hence case-by-case judgment is required. ${ }^{3}$

Perioperative use of ASA in noncardiac surgery is unlikely to reduce the risk of myocardial infarction or venous thromboembolism The POISE-2 (Perioperative Ischemic Evaluation 2) trial in 2014 found that preoperative use of ASA had no significant effect on the rate of postoperative myocardial infarction or venous thromboembolism. ${ }^{4}$ Use of ASA was associated with a $23 \%$ increase in major bleeding (HR 1.23, 95\% Cl 1.01-1.49). ${ }^{4} \mathrm{~A}$ guideline from the Canadian Cardiovascular Society indicates that ASA should not be started or continued 7 days before surgery except in patients with recent coronary stent insertion (within 6 weeks for bare-metal stents and 3-12 months for drug-eluting stents) or undergoing carotid endarterectomy. ${ }^{5}$

5 Acetylsalicylic acid should be used for patients with myocardial injury or ischemia after noncardiac surgery

The guideline from the Canadian Cardiovascular Society suggests that, postoperatively, patients with myocardial ischemia or myocardial injury (defined as a peak troponin T level of $>0.03 \mathrm{ng} / \mathrm{mL}$ ) should take ASA. ${ }^{5}$

\section{References}

1. Berger JS, Brown DL, Becker RC. Low-dose aspirin in patients with stable cardiovascular disease: a metaanalysis. Am J Med 2008;121:43-9.

2. Zheng SL, Roddick AJ. Association of aspirin use for primary prevention with cardiovascular events and bleeding events: a systematic review and meta-analysis. JAMA 2019;321:277-87.

3. The ASCEND Study Collaborative Group; Bowman L, Mafham M, Wallendszus K, et al. Effects of aspirin for primary prevention in persons with diabetes mellitus. N Engl J Med 2018;379:1529-39.

4. Devereaux PJ, Mrkobrada M, Sessler DI. Aspirin in patients undergoing noncardiac surgery. N Engl J Med 2014;370:1494-503.

5. Duceppe E, Parlow J, MacDonald P. Canadian Cardiovascular Society guidelines on perioperative cardiac risk assessment and management for patients who undergo noncardiac surgery. Can J Cardiol 2017;33:17-32.

\section{Competing interests: None declared.}

This article has been peer reviewed.

Affiliations: Departments of Internal Medicine (Koilpillai) and of Cardiac Sciences (Nishtala), University of Calgary, Calgary, Alta.

Correspondence to: Priya Koilpillai, priya.koilpillai@albertahealthservices.ca 